\title{
PENGENDALIAN HAMA DAN PENGOLAHAN BERAS MERAH MENDUKUNG PERTANIAN BERKELANJUTAN DI DUSUN SOPORARU, TAPANULI UTARA
}

\author{
Putri Chandra Ayu'1), Ameilia Zuliyanti Siregar ${ }^{1)}$, Haryati²) \\ 1)Program Studi Keteknikan Pertanian, Fakultas Pertanian, Universitas Sumatera Utara, Medan, Sumatera Utara, Indonesia \\ 2) Program Studi Agroteknologi, Fakultas Pertanian, Universitas Sumatera Utara, Medan, Sumatera Utara, Indonesia \\ Corresponding author : Putri Chandra Ayu \\ E-mail : pputricandra@usu.ac.id
}

\section{Diterima 22 September 2020, Direvisi 19 Oktober 2020, Disetujui 19 Oktober 2020}

\begin{abstract}
ABSTRAK
Dusun Soporaru merupakan salah satu dusun di Sumatera Utara yang memiliki beras spesifik lokal yaitu beras Natabo, yang merupakan beras super lokal milik petani sekitar dan sudah resmi dipasarkan. Namun, hingga saat ini infrastruktur bidang pertanian yang mendukung masih kurang memadai, seperti kebiasaan masyarakat dalam menggunakan bahan kimia untuk mengendalikan hama penyakit tanaman serta jumlah alat mesin pertanian untuk pengolahan padi yang masih belum tercukupi. Kegiatan ini bertujuan untuk membuat petani di desa mitra mengetahui potensi sumber daya alam bidang pertanian yang ada, khususnya padi beras merah, menerapkan konsep pengendalian hama terpadu dan bimbingan teknis pascapanen padi menggunakan mesin huller agar petani dapat mengolah hasil panen secara mandiri dan tepat guna sehingga kualitas dan kuantitas beras merah dari desa mitra meningkat. Pada kegiatan ini, dilakukan sosialisasi dan focus group discussion (FGD) dengan petani desa mitra untuk membahas masalah yang ada di lapangan selama ini, selanjutnya petani dibimbing untuk melakukan pengendalian hama padi tanpa bahan kimia yaitu dengan menggunakan alat perangkap jaring (sweep net) dan bimbingan teknis penggunaan mesin huller untuk tahap pascapanen padi. Kegiatan pengabdian masyarakat baik pada saat sosialisasi, diskusi maupun bimbingan teknis di lapangan telah terlaksana dengan baik dan mendapat respon positif dari petani di desa mitra
\end{abstract}

Kata Kunci : Padi beras merah; pengendalian hama terpadu; pascapanen padi.

\begin{abstract}
Soporaru Hamlet is a hamlet in North Sumatra that has local specific rice, namely Natabo rice, which is super local rice owned by local farmers and has been officially marketed. However, until now the supporting of agricultural infrastructure is still inadequate, the habit of using chemicals to control plant pests and the insufficient number of agricultural machinery for rice processing. This activity aimed to make the farmers in partner village know the potential of natural resources in agriculture in their village, especially the brown rice, to apply the concept of integrated pest control and post-harvest rice technical guidance using a huller machine so that farmers can process their crops independently and efficiently, so that the quality and quantity of brown rice from partner villages has increased. In this activity, socialization and focus group discussions (FGD) were carried out with partner village farmers to discuss problems in the field so far, then the farmers were guided to control rice pests without chemicals, namely by using sweep net tools and technical guidance using a huller machine for the post-harvest stage of rice. This community service activity that was consisted of socialization, discussion and technical guidance was conducted well and received a positive response from the farmers in the partner village.
\end{abstract}

Keywords: Brown rice; integrated pest control; post-harvest of rice.

\section{PENDAHULUAN}

Pada tahun 2019, dari data BPS SUMUT 2020, Kabupaten Tapanuli Utara menjadi penghasil padi nomor 6 terbesar di Provinsi Sumatera Utara dengan menyumbang $5,4 \%$ produksi padi dan beras yaitu masingmasing sebanyak 111 ribu ton dan 63,795 ribu ton. Dari data tersebut, dapat dilihat bahwa daerah ini memiliki potensi sumber daya alam bidang pertanian yang tinggi. Salah satu daerah penghasil padi di Kabupaten Tapanuli Utara yaitu Dusun Soporaru yang tepatnya terletak di Kecamatan Pangaribuan. Dusun ini memiliki sumber daya alam bidang pertanian yang tinggi, dengan komoditi yang dihasilkan masyarakat yaitu seperti padi, hortikultura dan palawija. Selain itu, sumber air di daerah ini juga cukup untuk memenuhi seluruh kegiatan budidaya pertanian yang berlangsung. Namun, pengetahuan masyarakat mengenai 
pengelolaan lahan dan hasil pertanian masih cukup rendah. Segala permasalahan dalam bidang pertanian masih diselesaikan dengan sistem konvensional.

Selain itu, permasalahan lain seperti akses jalan menuju Dusun Soporaru masih perlu mendapat perhatian lebih. Hal ini disebabkan karena masih terdapat sebagian jalan yang rusak bahkan berupa tanah liat. Hampir keseluruhan masyarakat daerah ini hidup dengan sumber penghasilan dari sektor pertanian, akan tetapi infrastruktur yang mendukung bidang pertanian masih kurang memadai.

Disamping permasalahan yang ada di Dusun ini, dapat dilihat juga adanya potensi besar yang dapat dikembangkan untuk memajukan perekonomian masyarakat. Salah satu potensi tersebut adalah sudah adanya beras spesifik lokal milik para petani desa yang disebut "beras Natabo". Pengambilan nama produk beras ini disesuaikan dengan bahasa daerah dari beras yang amat enak atau Natabo (Bahasa Batak). Beras Natabo ini merupakan beras super lokal yang dimiliki petani masyarakat sekitar dan sudah resmi dipasarkan.

Namun, permasalahan baru selalu muncul dalam proses budidaya dan pengolahan pascapanen padi yang merupakan akibat dari penyelesaian masalah yang sering dilakukan secara instan. Petani kerap kali menggunakan bahan kimia sebagai langkah awal membasmi hama dan penyakit pada lahan padi mereka. Hal ini disebabkan oleh diperolehnya hasil yang efektif dan efisien dalam mengendalikan hama dengan cara yang praktis dan menguntungkan petani (Arif, 2015). Tetapi dampak dari penggunaan materi kimia tersebut baru tampak di akhir dimana sehingga terjadi peledakan OPT di lahan pertanaman padi. Pada kondisi demikian populasi serangga hama akan meningkat apabila penggunaan pestisida tidak sesuai anjuran. Selain itu, penggunaan bahan kimia seperti pestisida bersifat bioaktif dan merupakan racun (Handayani et al., 2017). Oleh karena itu, perlu dilakukan Prinsip Pengendalian Hama Terpadu (PHT) meliputi pemanfaatan musuh alami, budidaya tanaman sehat dan pengamatan berkala. Prinsip PHT ini telah menjadi hal yang dominan dilakukan untuk perlindungan tanaman sejak tahun 1960-an (Horgan, 2017).

Selain itu, petani juga memiliki masalah dalam hal pengolahan pascapanen padi menjadi beras merah. Mesin penggiling padi yang digunakan pada lokasi mitra terbatas dan memiliki kekurangan yaitu proses pengupasan yang terlalu dalam dimana mengakibatkan penurunan mutu dan rendemen beras dari jumlah yang seharusnya dapat diperoleh. Rendemen beras giling dipengaruhi oleh perlakuan suhu dan lama penyimpanan, dan kisaran rendemennya yaitu antara 60,8067,80\% (Millati et al., 2018); (Hasbullah \& Dewi, 2012). Selanjutnya, salah satu faktor yang mempengaruhi parameter mutu beras yaitu kondisi (termasuk umur) mesin penggiling yang digunakan (Sarastuti et al., 2018). Selain itu, proses pengupasan yang terlalu dalam akan mengakibatkan butir beras yang dihasilkan memiliki ukuran, bentuk dan berat yang berkurang dari seharusnya atau dapat disebut kehilangan kualitas (quality loss) (Kumari \& Pankaj, 2015). Selain itu, penyusutan saat penggilingan ini juga merupakan salah satu faktor yang mengurangi hasil produksi beras disamping susut panen, susut perontokan dan susut pengeringan (Kobarsih \& Siswanto, 2015). Penyusutan-penyusutan tersebut dapat menyebabkan susut hasil hampir sebesar $21,09 \%$ (Iswari, 2012). Selain itu, terdapat beberapa faktor yang mempengaruhi susut pascapanen yaitu seperti varietas, umur panen, waktu musim panen, cara panen serta alat mesin pertanian yang digunakan (Hasbullah \& Dewi, 2012). Pada daerah mitra pengabdian, khususnya untuk faktor alat dan mesin pertanian yang digunakan dapat diatasi dengan menggunakan mesin penggiling padi dengan spesifikasi yang tepat.

Oleh karena itu, dengan dilakukannya kegiatan pengabdian kepada masyarakat ini dapat membantu petani di desa mitra untuk meningkatkan kualitas dan kuantitas padi beras merah di desa tersebut. Adapun tujuan dilaksanakannya kegiatan ini yaitu untuk membuat petani di desa mitra mengetahui potensi sumber daya alam bidang pertanian yang ada, khususnya padi beras merah, memberikan 1 set mesin huller, memberikan bimbingan teknis konsep pengendalian hama terpadu dan pascapanen padi menggunakan mesin huller agar petani dapat mengolah hasil panen secara mandiri dan tepat guna sehingga kualitas dan kuantitas beras merah dari desa mitra meningkat.

\section{METODE \\ Waktu dan Lokasi Kegiatan}

Kegiatan pengabdian masyarakat ini dilaksanakan oleh Tim Pengabdian Masyarakat Mono Tahun Dosen Muda Lembaga Pengabdian Kepada Masyarakat (LPM) Universitas Sumatera Utara terhadap masyarakat petani padi di Dusun Soporaru, Kecamatan Pangaribuan, Kabupaten Tapanuli Utara, Sumatera Utara pada bulan Mei Oktober 2020. 


\section{Realisasi Pemecahan Masalah}

Metode pendekatan yang dilakukan selama pelaksanaan program pengabdian adalah melalui Survei potensi/ permasalahan di Dusun Soporaru, Kecamatan Pangaribuan, Kabupaten Tapanuli Utara, Sumatera Utara.

Selanjutnya, yaitu kegiatan turun lapang yang oleh tim pengabdian masyarakat yang dibagi ke dalam beberapa kegiatan yaitu penyerahan 1 set mesin huller, focus group discussion (FGD), pelatihan, aksi/kegiatan dan pendampingan. Tim Pengabdian melakukan sosialisasi program melalui penyuluhan dan diskusi dengan masyarakat di Dusun Soporaru.

\section{HASIL DAN PEMBAHASAN Evaluasi}

Pelaksanaan kegiatan dilakukan dengan cara sosialisasi, bimbingan teknis di lapangan dan diskusi, oleh staf pengajar Fakultas Pertanian USU di Dusun Soporaru. Sosialisasi meliputi Pengetahuan Budidaya Tanaman Padi, Pengelolaan Hama Terpadu Tanaman Padi dan Pengolahan/ Penggilingan Padi Merah Tepat Guna (Gambar 2).

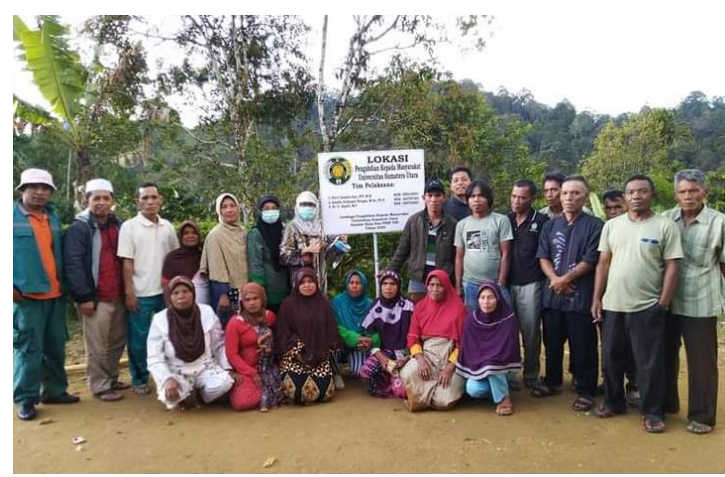

Gambar 1. Tim Pengabdian Masyarakat bersama dengan petani di Dusun Soporaru

Gambar 1 menunjukkan foto Tim Pengabdian Masyarakat bersama petani di Dusun Soporaru sebelum kegiatan dimulai. Selanjutnya, kegiatan dilanjutkan dengan pelatihan dan praktek di lapangan. Tim Pengabdian Masyarakat LPPM USU akan terus membimbing dan mendampingi hingga luaran yang diharapkan akan tercapai oleh Kelompok Mitra.

Pada kegiatan pengabdian masyarakat ini, pelatihan dan praktek lapangan yang dilakukan yaitu pelatihan atau bimbingan teknis penggunaan perangkap jaring dan mesin huller (pengupas gabah padi) yang dihibahkan kepada masyarakat dan petani desa mitra. Hal ini dilakukan karena walaupun teknologi seperti penanganan pascapanen, seperti penggilingan, sudah banyak tersedia, namun penerapannya di tingkat petani masih belum maksimal. Dimana kendala utamanya yaitu ketidaktahuan petani maupun masyarakat desa akan teknologi tersebut, yang bisa disebabkan oleh kurangnya promosi ke desa-desa, tidak adanya jasa penyewaan alat dan mesin pertanian pascapanen di sekitar petani dan ketidakmampuan petani maupun desa dalam pengadaan alat dan mesin pertanian tersebut (Swastika, 2012).

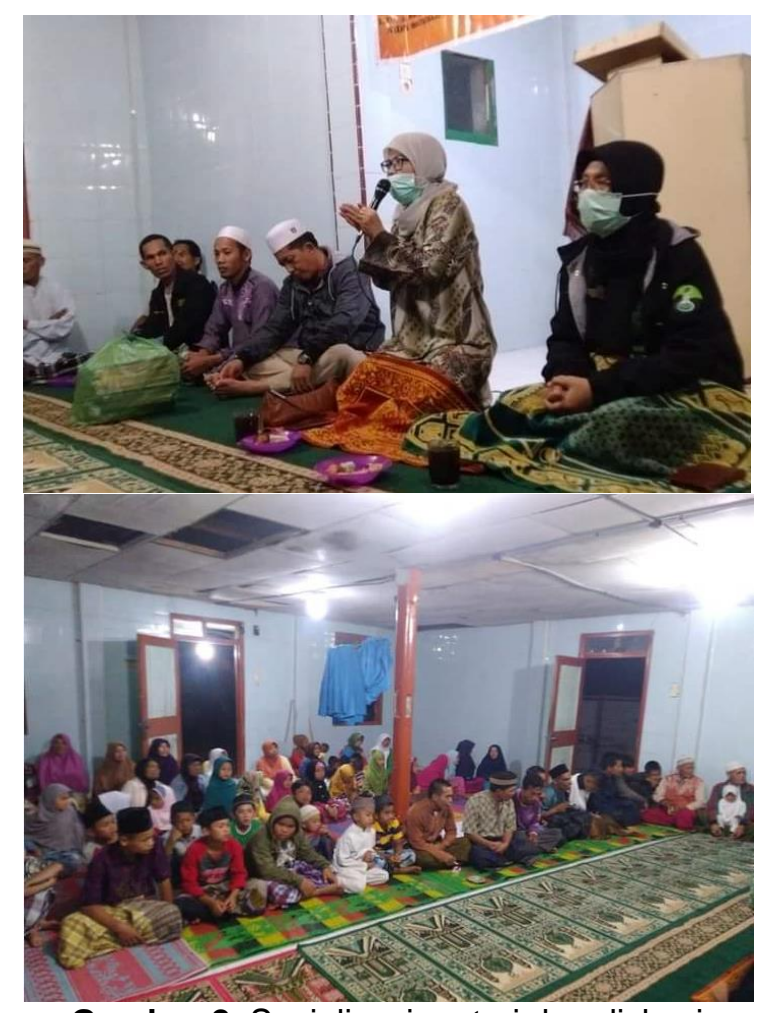

Gambar 2. Sosialisasi materi dan diskusi dengan petani

Perangkap jaring yang digunakan terbuat dari kain kasa bening yang mudah diayunkan untuk menangkap serangga yang dapat terbang di lahan. Penangkapan serangga dengan perangkap jaring dilakukan pada pagi hari pukul 07.00-09.00 WIB. Pelatihan penggunaan perangkap jaring ini dilakukan oleh masing-masing petani di lapangan ditunjukkan pada Gambar 3, diharapkan dengan penggunaan alat ini, penggunaan bahan kimia untuk mengendalikan hama dan penyakit tanaman padi di desa mitra dapat berkurang ataupun dihentikan. 


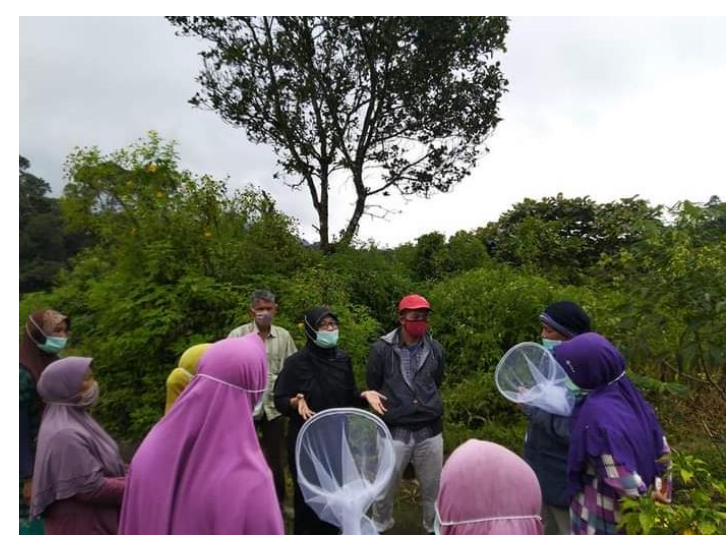

Gambar 3. Bimbingan teknis penggunaan perangkap jaring (sweep net) untuk pengendalian hama terpadu tanaman

Selanjutnya, bimbingan teknis pascapanen padi khususnya untuk tahap enggilingan gabah dilakukan dengan menggunakan mesin huller tipe AGR-RM80 dengan daya 1800 watt, dimensi $450 \times 310 \times$ $560 \mathrm{~mm}$, berat $35 \mathrm{~kg}$ dan kapasitas $260 \mathrm{~kg} / \mathrm{jam}$ (Gambar 4). Mesin ini memiliki beberapa kelebihan seperti mudah dioperasikan, mudah dimobilisasi, tingkat penggilingan (lebih dari $69 \%$ ) dan rendahnya kerusakan pada beras, sehingga sesuai untuk penggunaan kelompok petani dan masyarakat. Penggilingan padi merupakan proses pengupasan gabah menjadi beras dengan cara memisahkan lapisan lemma dan palea, selanjutnya mengeluarkan biji berasnya (Nugraha et al., 2007).

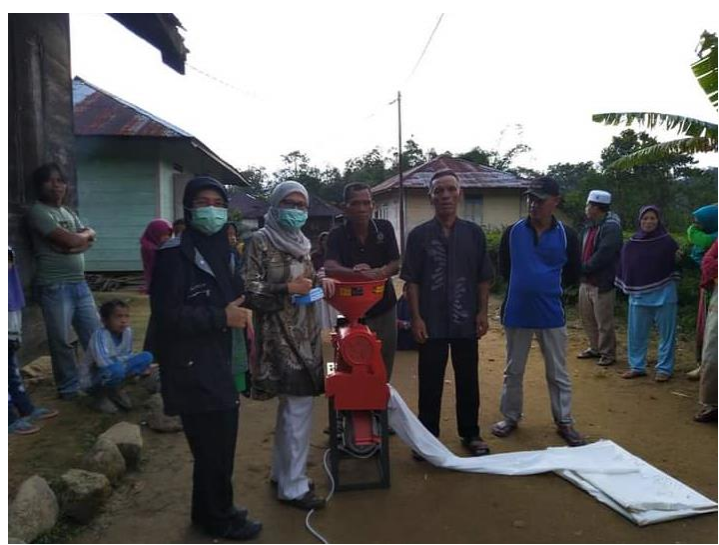

Gambar 4. Bimbingan teknis penggunaan mesin huller untuk mengupas gabah padi

\section{Faktor Pendukung}

Faktor pendukung dalam pelaksanaan pengabdian yang sangat membantu terealisasinya kegiatan ini yaitu adanya respon yang positif dari petani dan masyarakat di lokasi mitra, dimulai dari survey lokasi pengabdian, pembuatan proposal, pengiriman mesin dan peralatan saat pengabdian, hingga saat kegiatan sosialisasi dan pendampingan berlangsung. Respon positif ditunjukkan dengan sambutan yang baik saat kedatangan tim pengabdian ke lokasi dan antusiasme para petani saat kegiatan baik FGD maupun saat bimbingan teknis dilaksanakan.

\section{Faktor Penghambat}

Faktor penghambat dalam pelaksanaan pengabdian masyarakat ini yaitu akses jalan menuju Dusun Soporaru yang masih perlu mendapat perhatian lebih dikarenakan masih sebagian jalan rusak dan masih berupa tanah liat (Gambar 5). Untuk pengiriman barang sendiri, hanya bisa diantar sampai Desa Sigotom Julu, dimana masih membutuhkan waktu sekitar 30 menit untuk sampai ke Dusun Soporaru. Namun demikian, kegiatan tetap terlaksana dengan baik dengan partisipasi mitra di lokasi pengabdian.

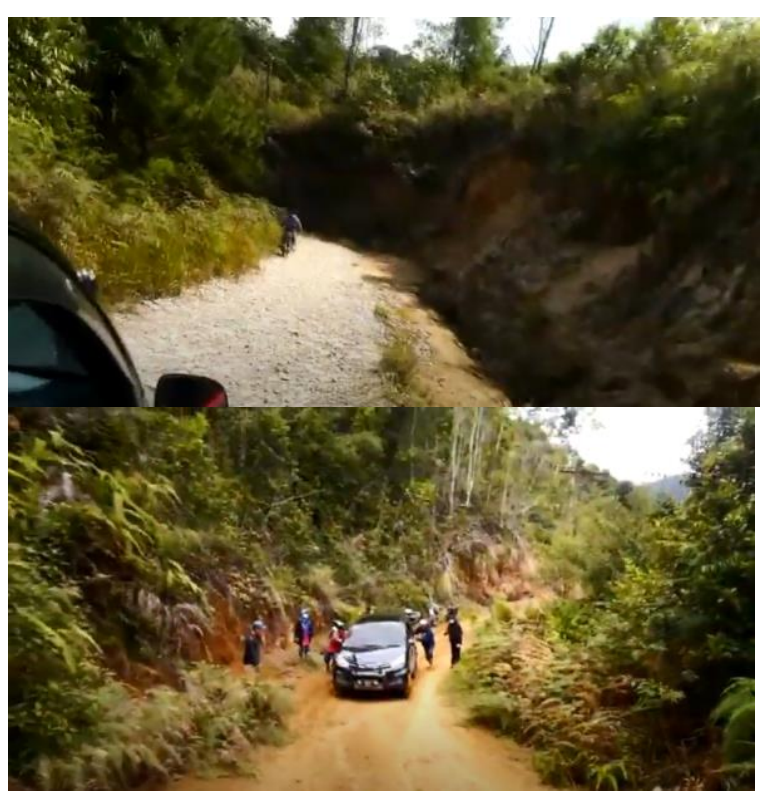

Gambar 5. Akses Jalan menuju Dusun Soporaru yang menjadi salah satu faktor penghambat dalam kegiatan

\section{SIMPULAN DAN SARAN}

Kegiatan pengabdian masyarakat mulai dari survei, sosialisasi, diskusi hingga bimbingan teknis di lapangan telah terlaksana dengan baik dan mendapat respon positif dari petani di desa mitra.

\section{UCAPAN TERIMAKASIH}

Pada kesempatan ini tim pelaksana PPM USU mengucapkan terima kasih kepada Universitas Sumatera Utara atas hibah yang diberikan melalui Skim Dosen Muda Sumber Dana Non PNBP USU T.A. 2020, Nomor: 291/UN5.2.3.2.1/ PPM/2020. 


\section{DAFTAR RUJUKAN}

Arif, A. (2015). Pengaruh Bahan Kimia Terhadap Penggunaan Pestisida Lingkungan. Journal of Chemical Information and Modeling, 53(9), 16891699.

Handayani, I. G. A. K. R., As'Adi, E., Hamzah, G., Leonard, T., \& Gunarto, G. (2017). Relationship between energy consumption in international market and Indonesia prices regulation. International Journal of Energy Economics and Policy, 7(5), 9-15.

Hasbullah, R., \& Dewi, A. R. (2012). Teknik penanganan pascapanen padi untuk menekan susut dan meningkatkan rendemen giling. Jurnal Pangan, 21(1), 17-28.

Horgan, F. G. (2017). Integrated pest management for sustainable rice cultivation: a holistic approach. 309342.

https://doi.org/10.19103/as.2016.0003. 23

Iswari, K. (2012). Kesiapan Teknologi Panen Dan Pascapanen Padi Dalam Menekan Kehilangan Hasil Dan Meningkatkan Mutu Beras. Jurnal Penelitian Dan Pengembangan Pertanian, 31(2), 30904.

https://doi.org/10.21082/jp3.v31n2.201 2.p\%p

Kobarsih, M., \& Siswanto, N. (2015). Penanganan Susut Panen dan Pasca Panen Padi Kaitannya dengan Anomali Iklim di Wilayah Daerah Istimewa Yogyakarta. Planta Tropika: Journal of Agro Science, 3(2), 100-106. https://doi.org/10.18196/pt.2015.046.1 00-106

Kumari, A., \& Pankaj, P. P. (2015). Agricultural products. Post Harvest Losses of Agricultural Products: Management and Future Challenges in India, June, 64-74.

https://doi.org/10.30875/e1fcbe14-en

Millati, T., Pranoto, Y., Bintoro, N., \& Utami, T. (2018). Pengaruh Suhu Penyimpanan pada Gabah Basah yang Baru Dipanen terhadap Perubahan Mutu Fisik Beras Giling. Agritech, 37(4), 477. https://doi.org/10.22146/agritech.1201 5

Nugraha, S., Thahir, R., Besar, B., \& Pascapanen, P. (2007). Keragaan Kehilangan Hasil Pascapanen Padi pada 3 (Tiga) Agroekosistem. Buletin Teknologi Pasca Panen, 3(1), 42-49.

Sarastuti, Ahmad, U., \& Sutrisno. (2018). Analisis Mutu Beras dan Penerapan
Sistem Jaminan Mutu dalam Kegiatan Pengembangan Usaha Pangan masyarakat. 15(2).

Swastika, D. K. S. (2012). Teknologi Panen dan Pascapanen Padi: Kendala Adopsi dan Kebijakan Strategi Pengembangan. 331-346. 